\title{
Influence of the parameters of the hydrothermal carbonization of the biomass on the biocoal obtained from peat
}

\author{
Kristina Krysanova ${ }^{1 *}$, Alla Krylova ${ }^{1}$, Victor Zaichenko ${ }^{1}$, Vladimir Lavrenov ${ }^{1}$, Vladimir Khaskhachikh $^{1}$ \\ ${ }^{1}$ Joint Institute for High Temperatures of Russian Academy of Sciences, Izhorskaya 13, str. 2, Moscow, Russia
}

\begin{abstract}
Hydrothermal carbonization is modern low-temperature method to improve characteristics of peat and other types of biomass as a fuel. The influence of methods at different temperatures and different reaction time the physical-chemical and energy properties of the resulting biochar is studied. Characteristics of the initial peat and hydrochar were determined such as elemental composition, ash content, moisture content, heating values. It has been established that with an increase in temperature and reaction time, yield of hydrochar oxygen in it decreases (from $33.1 \%$ - initial peat to $19.47 \%$ - hydrochar obtained at $230{ }^{\circ} \mathrm{C}$ ), but carbon (from $52.09 \%$ - initial peat to $68.17 \%$ - hydrochar obtained at $230{ }^{\circ} \mathrm{C}$ ) and heating value increases. Also was observed leaching the inorganic component from hydrochar into the water.
\end{abstract}

\section{Introduction}

Peat is a combustible mineral of plant origin and the precursor of the genetic series of coals. Peat is also a renewable source of energy and its accumulation occurs constantly. Therefore, its rational use will allow achieving a large economic effect while minimizing damage to natural ecosystems.

According to expert estimates a huge reserves of peat are deposited in Russia (about 150 mlr. tonn). Annual natural growth of peat reserves in Russia will be more than 1 billion $\mathrm{m} 3$. Unfortunately, the extensive deposits of minerals are practically not used at present. In the mid-1970s, the extraction of peat used for energy purposes amounted to about 50 million tons per year, however, it has now decreased to $1.5-3$ million tons per year.

However, peat as a fuel has a number of disadvantages such as high moisture content and low thermal characteristics, so it could not be co-burnt with coil. So it would be useful to pretreat peat with the aim of its fuel properties enhancement.

The modern method to improve characteristics of a renewable biomass including peat is hydrothermal carbonization (HTC). HTC sometimes called wet torrefaction or wet mild pyrolysis. The main product of HTC is hydrochar, that has a higher energy density, lower moisture and mineral content compared to raw biomass. Hence, obtained hydrochar is easier to transport and store.

HTC carried out at temperatures from 180 to $280{ }^{\circ} \mathrm{C}$, in aerobic conditions and in presence of subcritical liquid water [2]. One of the main advantages of this process is the possibility to pretreat biomass with high moisture [3].
The main aim of this paper is the investigation of the temperature and reaction time influence on physicochemical properties of the resulting biochar obtained via HTC

\section{Material and methods}

\subsection{Initial raw material}

The initial peat was characterized by a $34 \%$ moisture content and a relatively low ash content $(9.3 \%)$. The elemental composition of peat (wt. \%) was the following: nitrogen, 1.42; carbon, 52.09; hydrogen, 5.72; sulfur, 0.15 ; and oxygen, 31 . The yield of volatile substances was $80 \%$. The net and gross calorific values were 20.2 and $21.5 \mathrm{MJ} / \mathrm{kg}$, respectively.

\subsection{Hydrothermal carbonization: experimental procedures}

Hydrothermal carbonization was conducted at four temperatures such as $160,190,210$, and $230{ }^{\circ} \mathrm{C}$ (these experiments were carried out in a previous study [4] ) and for reaction durations $1 \mathrm{~h}$,. Stainless steel batch reactor was used. Raw material with weight of mfeed $=50$ $\mathrm{g}$ was mixed with water in ratio $1: 3$ and then placed into reactor. If necessary catalyst was added into the mixture. The reactor was heated to the required temperature and held for 8 hours. Then the reactor was cooled down to room temperature. The resulting suspension was separated on filter paper into a solid residue and liquid. Filtration paper with a pore size of 3-5 $\mu \mathrm{m}$ was folded and placed in a glass funnel. The suspension was poured onto the filter paper and filtration occurred naturally 
without additional influences. Solid residue dried at 20 ${ }^{\circ} \mathrm{C}$ for 48 .

\subsection{Analytical methods}

A SDTQ 600 thermal analyzer, which allows simultaneous thermal analysis including thermogravimetric and differential thermogravimetric analysis and differential scanning calorimetry, was used to determine the moisture and ash contents of compounds.

The calorific values of materials were determined based on elemental analysis, which was carried out on a Vario MICRO Cube elemental analyzer intended for the simultaneous determination of the elements $\mathrm{C}, \mathrm{H}, \mathrm{N}$, and $\mathrm{S}$ in the samples. Oxygen $(\mathrm{O}$, wt.\%) for dry state was calculated from material balance:

$$
\mathrm{O}=100-(\mathrm{C}+\mathrm{H}+\mathrm{N}+\mathrm{S}+A)
$$

where $\mathrm{C}, \mathrm{H}, \mathrm{N}, \mathrm{S}, \mathrm{A}$ are the content of carbon, hydrogen, nitrogen, sulfur and ash calculated on dry basis. The heating values were calculated from the Mendeleevs equation on the basis of elemental composition [5]:

$$
\begin{aligned}
& \mathrm{HHV}=0.339[\mathrm{C}]+1.256[\mathrm{H}]+0.109[\mathrm{~S}]-0.109[\mathrm{O}] \\
& \mathrm{LHV}=0.339[\mathrm{C}]+1.256[\mathrm{H}]+0.109[\mathrm{~S}]-0.109[\mathrm{O}]- \\
& 0.0252[9 \mathrm{H}+W]
\end{aligned}
$$

where HHV, LHV are the highest and lowest calorific values respectively, $\mathrm{kJ} / \mathrm{kg} ; \mathrm{C}, \mathrm{H}, \mathrm{O}, \mathrm{S}, W$ are carbon, hydrogen, oxygen, combustible sulfur and moisture calculated on dry basis, wt.\%. The mass yield ym describes a percentage of raw material remaining in biochar and it is calculated as the ratio of carbonized product in weight $\left(\mathrm{m}_{c}\right)$ to raw biomass weight $\left(\mathrm{m}_{b}\right), \%$ :

$$
\mathrm{y}_{\mathrm{m}}=\frac{\mathrm{m}_{\mathrm{c}}}{\mathrm{m}_{b}}
$$

The energy yield ye indicates a percentage of feedstock caloricity remains in the solid residue, $\%$. The index is calculated as:

$$
\mathrm{y}_{\mathrm{e}}=\mathrm{y}_{\mathrm{m}} \frac{\mathrm{HHV}_{\mathrm{c}}}{\mathrm{HHV}_{\mathrm{b}}}
$$

where $\mathrm{HHV} c$ and $\mathrm{HHV} b$ are the highest heating values of product and feedstock respectively.

\section{Results and discussion}

\subsection{Yields}

Fig.1 shows the effect of two different operating parameters on mass and energy yields of initial peat: reaction time, reaction temperature, catalyst presence.

As expected, the mass yield of hydrochar samples was reduced with an increase in the reaction time and temperature. The greatest influence in a series of experiments is observed in the case of reaction time. The maximum difference was $27 \%$ between samples obtained at $1 \mathrm{~h}$ and $8 \mathrm{~h}$. The graph shows that the mass yield varies with time inversely.

It is not surprising that the sample had the smallest mass yield with the longest reaction time and highest temperature $\left(230{ }^{\circ} \mathrm{C}, 8 \mathrm{~h}\right)$ and was only $52.8 \%$.

The addition of citric acid catalyst has virtually no effect on the mass yield of the hydrochar. The decrease in mass yield with an increase in the severity of HTC is explained by the chemical reactions that take place in the process. The main reactions that take place during HTC: hydrolysis, dehydration, decarboxylation, aromatization and polymerization. Hydrolysis is one of the most significant reactions in the process and goes at the first step of HTC [6]. Degree of hydrolysis of polysaccharides increases with temperature and reaction time in direct ratio. Hence, degree of depolarization increases and the mass yield decreases accordingly.

The yield of the sample with the addition of citric acid and $\mathrm{pH} 4.5$ was lower than that of the sample without, since the acid intensifies hydrolysis, and therefore depolymerization.

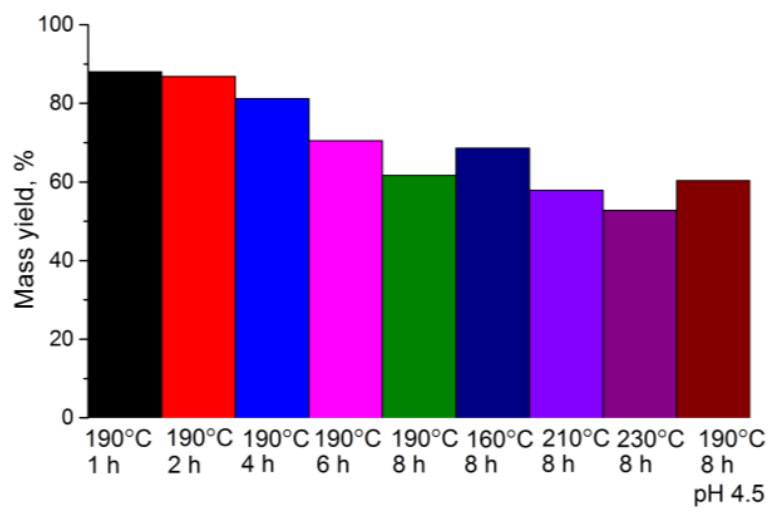

Fig. 1. Mass yield of hydrochar.

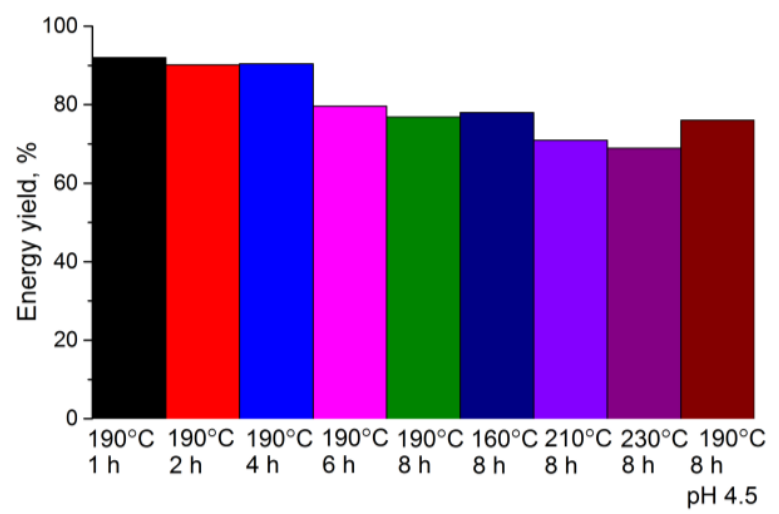

Fig. 2. Energy yield of hydrochar.

\subsection{Element analisys and heating values}

Elemental composition of initial peat and biochar produced via hydrothermal carbonization at different operation conditions are presented at Table 1. 
Table 1. Elemental composition of initial peat and hydrochars.

\begin{tabular}{|l|c|c|c|c|c|c|}
\hline \multirow{2}{*}{ Material } & \multicolumn{7}{|c|}{ Elemental analysis, wt.\% } \\
\cline { 2 - 7 } & $\mathrm{N}$ & $\mathrm{C}$ & $\mathrm{H}$ & $\mathrm{O}$ & $\mathrm{S}$ & $\mathrm{A}$ \\
\hline $\begin{array}{l}\text { Initial } \\
\text { peat }\end{array}$ & 1.42 & 52.09 & 5.72 & 31.00 & 0.15 & 9.63 \\
\hline $\begin{array}{l}\mid 7 \\
190^{\circ} \mathrm{C},\end{array}$ & 1.54 & 55.91 & 5.71 & 38.55 & 0.11 & 2.87 \\
\hline $\begin{array}{l}190^{\circ} \mathrm{C}, \\
2 \mathrm{~h}\end{array}$ & 1.74 & 56.38 & 5.36 & 32.65 & 0.14 & 3.72 \\
\hline $\begin{array}{l}190^{\circ} \mathrm{C}, \\
4 \mathrm{~h}\end{array}$ & 1.64 & 58.60 & 5.73 & 29.19 & 0.19 & 4.64 \\
\hline $\begin{array}{l}190^{\circ} \mathrm{C}, \\
6 \mathrm{~h}\end{array}$ & 1.97 & 60.24 & 5.38 & 26.93 & 0.16 & 5.33 \\
\hline $\begin{array}{l}190^{\circ} \mathrm{C}, \\
8 \mathrm{~h}\end{array}$ & 2.12 & 64.84 & 5.71 & 22.13 & 0.15 & 5.05 \\
\hline $\begin{array}{l}160^{\circ} \mathrm{C}, \\
8 \mathrm{~h}\end{array}$ & 1.8 & 60.5 & 5.76 & 30.51 & 0.13 & 1.30 \\
\hline $\begin{array}{l}210^{\circ} \mathrm{C}, \\
8 \mathrm{~h}\end{array}$ & 1.92 & 64.89 & 5.36 & 22.16 & 0.09 & 5.58 \\
\hline $\begin{array}{l}230^{\circ} \mathrm{C}, \\
8 \mathrm{~h}\end{array}$ & 1.97 & 68.17 & 5.6 & 19.47 & 0.11 & 4.68 \\
\hline $\begin{array}{l}190^{\circ} \mathrm{C}, \\
8 \mathrm{~h}, \\
\mathrm{pH} 4.5\end{array}$ & 2.06 & 65.49 & 5.82 & 22.45 & 0.14 & 4.04 \\
\hline
\end{tabular}

Due to the data showed in table 1 it could be said that all the samples made by HTC were carbonized and deoxygenated compared to the initial peat. Again, this is due to chemical reactions that provoke a decrease in oxygen and ash in samples, specially dehydration and decarboxylation of hydrolyzed products [7]

Hydrothermal treatment of peat at a relatively low temperature $\left(160{ }^{\circ} \mathrm{C}\right)$ increased the carbon concentration to $60.5 \%$ compared to initial peat, and an increase in the treatment temperature $\left(230{ }^{\circ} \mathrm{C}\right)$ made it possible to increase it to $68.17 \%$. At the same time, a decrease in the oxygen content of the sample by almost $10 \%$ was observed.

With an enhance in the reaction time, carbon increases ( from $55.91 \%$ at $1 \mathrm{~h}$ to $64.84 \%$ at $8 \mathrm{~h}$ ) and oxygen decreases (from $33.51 \%$ at $1 \mathrm{~h}$ to $22.13 \%$ at $8 \mathrm{~h}$ ). The addition of citric acid catalyst increases carbon (from $64.84 \%$ pure sample to $65.49 \%$ sample with catalyst).

An interesting trend is observed in the case of ash content in samples.

In the case of hydrothermal carbonization, unlike other thermal methods, mineral components are washed into the water and there is a noticeable decrease. The similar trend for inorganics removing from biomass in water during HTC is described in [8]. This is due to the destruction of lignocellulose, in which there is a large amount of mineral components. Under hydrothermal conditions, the depolymerisation of hemicellulose and cellulose takes place, which results in the formation of slightly porous structures of hydrochars [9]. It has been reported that these porous structures may allow the leaching metals that were previously held/bonded in the cross-linked matrix structure of biomass into the liquid form [10].

During HTC, in addition to ash leaching, concentration process due to the destruction of the structures is observed too. Therefore, it is difficult to assume the exact amount of ash in the obtained sample.

The smallest amount of ash is observed in the sample obtained at $160{ }^{\circ} \mathrm{C}$ (ash $-1.3 \%$, which is 7 times less than that of the initial peat $(9.63 \%)$. With an increase in the duration of the reaction ( from $2.87 \%$ at $1 \mathrm{~h}$ to $5.05 \%$ at $8 \mathrm{~h}$ ), ash increases in percentage, which is associated with an increase in the depolymerization of feedstock.

Heating values (Fig. 3) reliably dependent on carbon and oxygen in the material. With increasing amounts of oxygen and decreasing oxygen, the calorific value will Increase. Therefore, the highest heating values will be obtained by a sample obtained at $230{ }^{\circ} \mathrm{C}(26.77$ - LHV, $28.03-\mathrm{HHV}, \mathrm{MJ} / \mathrm{kg}$ ) as having less carbon and oxygen.

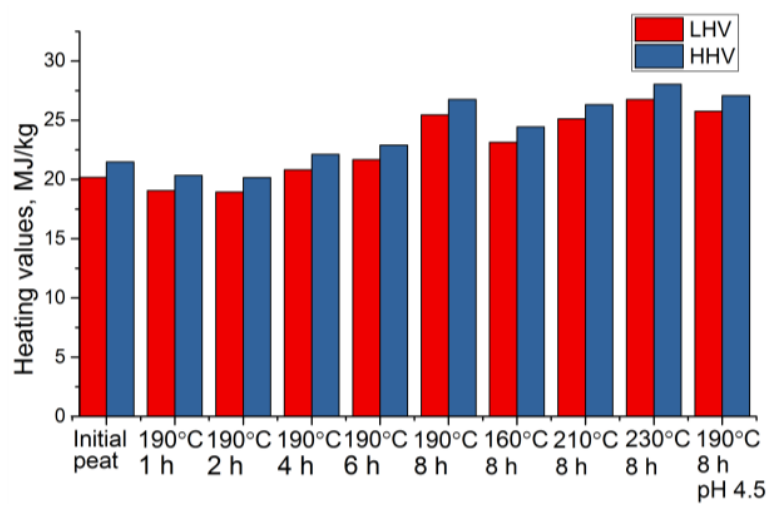

Fig. 3. Heating values of initial peat and hydrochars.

During the process, cellulose and hemicellulose have the least stability, unlike lignin, which has the highest heating value among those mentioned above. After the destruction of cellulose and hemicellulose, lignin remains, thereby increasing the calorific value of obtained hydrochar. Furthermore under subcritical water conditions the degradation of hemicellulose and cellulose a huge amount monomers are formed like furfurals, and 5-Hydroxyl Methyl Furfural (HMF) which have a higher heating values then cellulose and hemicellulose [11].

These intermediates increase energy yield and HHV by precipitating into the porous structure of hydrochar [12]. The increase in the duration and reaction time is accompanied by an increase in heating values, such dependencies are described in the literature [13].

\subsection{Van Krevelen diagram}

The variation of the $\mathrm{O} / \mathrm{C}$ and $\mathrm{H} / \mathrm{C}$ atomic ratios indicates the degree of deoxygenation of biomass by decarboxylation, dehydration or demethanation The reduction of $\mathrm{O} / \mathrm{C}$ atomic ratio mainly attributed to dehydration and decarboxylation, while that of $\mathrm{H} / \mathrm{C}$ atomic ratio is related to the dehydration and increased degree of aromatization [14]. Materials with low O/C and $\mathrm{H} / \mathrm{C}$ could avoid energy losses in combustion., so the closer sample to the 0 in Van Krevelen diagram the better fuel properties it has.

As shown in Fig. 4, the reduction of $\mathrm{O} / \mathrm{C}$ and $\mathrm{H} / \mathrm{C}$ atomic ratios illustrated the important improvments of 
hydrochar obtained by HTC thought dehydration and decarboxylation.

With an increase in the severity of the reaction, the samples move closer to exactly 0 on the van Krevelen diagram, and therefore have better thermal characteristics. Both temperature and reaction time influence the performance improvement and the samples are shifted.

Thus the main reactions affect the properties of hydrachar are decarboxylation and dehydration, but not demethanation. Similar trends are observed in the literature [15].

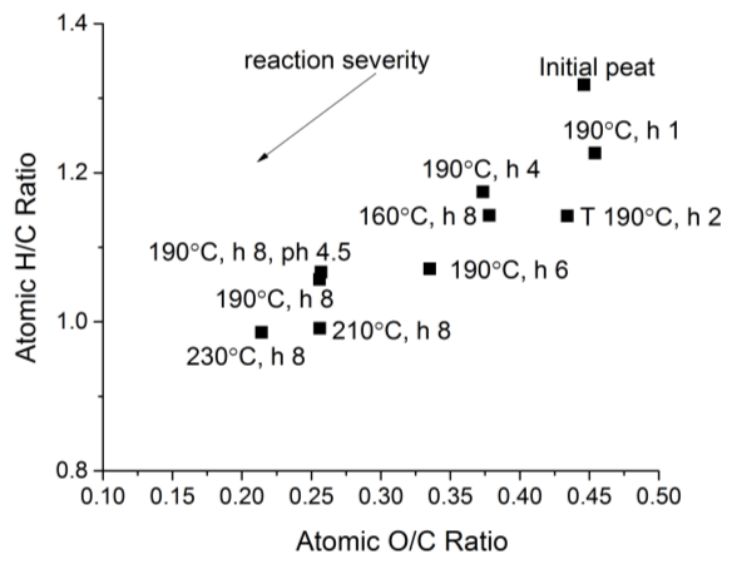

Fig. 4. Diagram van Krevelen.

\section{Conclusions}

Hydrothermal reaction is a modern method of processing various types of biomass for producing biocoal with high thermal physical properties close to that of fossil fuel such as coal.

Hydrothermal carbonization of peat has demonstrated the ability to process biomass without pretreatment particularly drying.

The reaction times, temperature, the presence of a catalyst significantly affect the resulting hydrochar. The most important parameter influencing the process is the temperature.

As a result, the work revealed the following dependencies: with an increase in temperature and reaction time, yield of hydrochar and oxygen decreases, but carbon and heating value increases. Catalyst addition had little effect on properties of hydrochar, however, most likely influenced the reaction rate. Also was observed leaching the inorganic component from hydrochar into the water.

\section{References}

1. V.V. Panov, O.S. Misnikov, Modern trends in the development of the peat industry in Russia. Trydi Instorfa 11 pp. 3-12.(2018)

2. S.S.A. Syed-Hassan, Y. Wang, S. Hu, S. Su and J. Xiang, Thermochemical processing of sewage sludge to energy and fuel: Fundamentals, challenges and considerations. Renewable and Sustainable Energy Reviews $\quad 80$ pp. 888-913 ( 2017) doi: 10.1016/j.rser.2017.05.262

3. M. Reza, Hydrothermal carbonization of lignocellulosic biomass, Ph.D. thesis (2013).

4. K.O. Krysanova, V.M. Zaichenko, G.A. Sychev et al. Solid Fuel Chem. 52 pp. 370 (2018).

5. S. D. Beskov, Technochimicheskie rascheti, Vishaya sckola: Chimiya, Moscow (1962).

6. T. Wang, Y. Zhai, Y. Zhu, C. Li, G. Zeng, Guangming, A review of the hydrothermal carbonization of biomass waste for hydrochar formation: Process conditions, fundamentals, and physicochemical properties. Renewable and Sustainable Energy Reviews 90 (2018).

7. M. Sevilla, A. Fuertes, The production of carbon materials by hydrothermal carbonization of cellulose. Carbon 47 pp. 2281-2289 (2009) doi:10. 1016/j.carbon.2009.04.026.

8. A. Smith, S. Singh, A. Ross, Fate of inorganic material during hydrothermal carbonisation of biomass: Influence of feedstock on combustion be-haviour of hydrochar. Fuel 169 135-145 (2016).

9. A. Funke, F. Ziegler, Hydrothermal carbonization of biomass: a summary and discussion of chemical mechanisms for process engineering. Biofuels, Bioprod Biorefin 160 pp. 77 (2010).

10. M.T. Reza, J.G. Lynam, M.H. Uddin, C.J. Coronella, Hydrothermal carbonization: fate of inorganics. Biomass Bioenergy 49 pp. 86-94 (2013).

11. T. R. K. C. Doddapaneni, R. Jain, P. Ramasamy, J. Rintala, H. Romar, J. Konttinen, Adsorption of furfural from torrefaction condensate using torre_ed biomass. Chemical Engineering Journal 334 pp. 558 (2018) doi:10.1016/j.cej.2017.10.053.

12. H. Kambo, A. Dutta, Comparative evaluation of torrefaction and hydrothermal carbonization of lignocellulosic biomass for the production ofsolid biofuel. Energy Conversion and Management 105 pp. 746 (2015)

13. R. Pradhan, Bio-carbon Production by Oxidation and Hydrothermal Carbonization of Paper Recycling Black Liquor. Journal of Cleaner Production 213 (2018) 10.1016/j.jclepro.2018.12.175.

14. H. Liu, C. Yingquan, Y. Haiping, F. Gentili, Francesco, U. Söderlind, X. Wang, W. Zhang, H. Chen, Hydrothermal carbonization of natural microalgae containing a high ash content. Fuel. 249 pp. 441-448 (2019) 10.1016/j.fuel.2019.03.004.

15.Z. Yao, X. Ma, Hydrothermal carbonization of Chinese fan palm. Bioresource Technology 282 (2019) 10.1016/j.biortech.2019.02.130. 